\title{
Experimental stock market dynamics: Excess bids, directional learning, and adaptive style-investing in a call-auction with multiple multi-period lived assets
}

\author{
Reinhard Selten ${ }^{\mathrm{a}}$, Tibor Neugebauer ${ }^{\mathrm{b}, *}$ \\ ${ }^{a}$ University of Bonn, Germany \\ ${ }^{\mathrm{b}}$ University of Luxembourg, 6, rue Richard Coudenhove-Kalergi, 1359 Luxembourg, Luxembourg, Germany
}

\section{A R T I C L E I N F O}

\section{Article history:}

Received 3 April 2016

Revised 3 September 2017

Accepted 14 April 2018

Available online 5 May 2018

\section{JEL code:}

C90

D53

G02

G11

G12

Keywords:

Call market experiment

Market dynamics

Excess bids

Bounded rationality

Adaptation

Style-investing

Learning direction theory

\begin{abstract}
A B S T R A C T
We study the behavioral dynamics of limit orders in simultaneous experimental callauction markets with multiple multi-period lived securities. As analytical decision variable we use excess bids; the number of submitted bids minus the number of offers. The feedback variable is (excess) return. Our results suggest that excess bids are predictive of qualitative asset returns, and that excess bids are formed in an adaptive way. We conclude that the price trend or reversal is reinforced by rejected excess bids and the fundamental laws of demand and supply instigate a regression to the mean. Our analysis of portfolio adjustment dynamics which is based on learning direction theory shows that adaptive value-style investing and path-dependence explain a significant share of individual behavior.
\end{abstract}

(C) 2018 Published by Elsevier B.V.

\section{Introduction}

We study the behavioral dynamics of limit orders in simultaneous two-sided experimental call markets with multiple multi-period lived assets. Using a top-down approach, we analyze the price dynamics of the market portfolio, the market dynamics of the single asset and the behavior of the individual trader. Our foremost research question is if the individual portfolio adjustment dynamics can be explained by models of adaptive behavior, in particular, learning direction theory (Selten and Stoecker, 1986). On a more general level we ask the question if price formation is an adaptive process. - Based

\footnotetext{
Financial support by the Deutsche Forschungsgemeinschaft is acknowledged (GZ: SE 137/6-1). The scientific research presented in this publication has also been given financial support by the National Research Fund of Luxembourg (F2R-368 LSF-PMA-13SYSB). The authors acknowledge helpful comments by Peter Bossaerts, Cars Hommes, Michael Kirchler, Charlie Plott and conference participants at WEHIA Nice 2015, and Experimental Finance Mannheim 2016.

* Corresponding author.

E-mail address: tibor.neugebauer@uni.lu (T. Neugebauer).
} 
on our experimental data the answers to both questions are affirmative. Qualitative returns are predictable, and trader behavior is predictable in our setting too. Our results suggest that individual interactions and market dynamics are subject to adaptation and equilibration and portfolio adjustments follow the suggested directional learning pattern.

Learning direction theory suggests qualitative adjustments in the direction of the ex post best response. Selten and Buchta illustrate learning direction theory by their analogy of an (autodidactic) archer who learns how to hit a trunk with an arrow. "If he misses the trunk to the right, he will shift the position of the bow to the left and if he misses the trunk to the left he will shift the position of the bow to the right. The marksman looks at his experience from the last trial and adjusts his behavior" (Selten and Buchta, 1999, p. 86). Learning direction theory has been applied in many different simple repeated decision environments and shown to explain the behavior (see Selten, 2004) including (single-period) call markets (Cason and Friedman, 1997). Learning direction theory implies for repeated decisions that (if a change occurs) decisions are changed in the direction of ex-post payoff maximization rather than in the opposite direction. In simple decision environments the response mode to directional learning is simple since feedback is one-dimensional if the environment in which the new environment is an exact replication of the old one. In more complex environments, feedback can be multi-dimensional due to environmental changes and multiple response modes can exist. For example in our case; suppose an (autodidactic) investor tries to achieve a maximum return in portfolio choice with multiple multi-period lived assets. The investor's feedback informs about the returns on every financial security in the past period, and about security metrics like the market capitalization, earnings, and book value before and after the period. The feedback therefore contains the information, e.g., if small-cap stock portfolios achieved a higher or lower return than large-cap stock, or, e.g., if high-value stock portfolios achieved a higher or lower return than low-value stocks. Given the changes in the metrics between periods, the decision environment is never an exact replication of itself and therefore multiple response modes are possible. The investor's response mode depends on the metric of focus. An important question regarding learning in complex environments is what response mode the decision maker selects.

Following the literature (Barberis and Shleifer, 2003), we call the response modes investment styles in our study of portfolio adjustment dynamics. According to Barberis and Shleifer, investors group assets in styles like momentum, value and size and move funds among these styles according to their relative performance. The literature suggests static investment styles like small-minus-big SMB for size-style investing or high-minus-low HML for value-style investing. In sharp contrast, we propose an adaptive version of these investment styles through integration with learning direction theory. We analyze the learning dynamics across different response modes with experimental data, and based on the fit of the models we are able to select value-style investing as predominant response mode in our environment. We also find that value-style investing moves from the adaptive model closer to its static pendant over time.

As analytical decision tool we use subjects' excess bids, that is, the number of bids minus the number of offers. Before focusing the analysis on directional learning, we discuss the properties of the excess bids variable in our data. Excess bids have been suggested as proxy for Walrasian excess demand (Walras 1954, Smith et al., 1988; Van Boening, 1991, 2012). ${ }^{1}$ Smith et al. studied the market dynamics of a multi-period lived single asset to find that excess bids are positively correlated to subsequent price changes. Accordingly, the price in the subsequent period is more likely to rise than to fall if the excess bids variable is positive, and vice versa (see also Plott, 2008a). Smith et al. coined this pattern the Walrasian adaptive price adjustment hypothesis suggesting that excess bids predict trader excess demand in the next period. Smith et al. interpreted this finding as supportive evidence of the rational expectation hypothesis. Van Boening (1991, 2012) repeated the analysis of Smith et al. in the corresponding call auction market. He reports that excess bids effects are robust across the two market organizations, but found that the effect in the call auction is smaller in magnitude than in the continuous double auction. In the context of real-world data, evidence has shown that net open interest (a real-world market proxy of rejected excess bids) of stock option is one of the significant variables in the determination of the US future spot price of the underlying share (e.g., Bhuyan and Chaudhury, 2005).

We contribute to the literature on excess bids by analyzing multiple multi-period lived assets and by studying the formation of excess bids. In fact, our data confirm that the excess bids variable heralds subsequent stock returns. In contrast to the received literature which focuses on the predictive characteristics of the excess bids variable, nonetheless, we also examine its adaptive characteristics. The excess bids variable reveals path dependence; the rejected excess bids are reentered in the subsequent period and they are reentered at an enhanced level. Based on our data, we conclude the excess bids variable behaves like an adaptive process. The excess bids submitted at market opening are highly correlated to subjects' prior rejected excess bids. In other words, there is a path-dependence between current excess bids and past excess bids. In line with the adaptive model, rejected excess bids are adjusted in the direction of the ex-post best reply. Subjects tend to increase rejected bids and decrease rejected offers in the following period. The adaptive model of excess bids suggests that market prices trend between periods. Over many periods we also observe Marshallian market dynamics (e.g.,

\footnotetext{
1 A few other studies investigate the dynamics of experimental markets exhausting more information from excess demand than excess bids does to study price discovery and equilibration within a period. Asparouhova, Bossaerts and Plott (2003) and Bossaerts and Plott (2008) suggest that the jaws in the order book provide further relevant information to predict the short term motion of the market. Incorporating the information of the jaws in the book, Plott and Pogorelskiy (2015) are able to predict to a good extent the individual interactions prior to the second call of a double call auction market where buyers and sellers have multiple values. In contrast to these studies, our environment involves multi period lived assets and the uncertainty in our environment regarding cash flows would make it impossible for subjects to compute an equilibrium market clearing price. One should note that there is also a small but growing experimental literature on price discovery; see Plott (2008a) for a brief survey and key results of the literature.
} 
Asparouhova et al., 2016); bids outnumber offers when returns are high and vice versa. Our analysis of the evolution of decision making indicates that adaptive behavior, subjects' interactions and fundamental values shape the market dynamics.

The results discussed in the paper are based on the data from our experiments with the multiple unit call auction market (Selten and Neugebauer, 2013). We propose our analysis as a first approach of learning direction theory to complex environments, in particular, to security markets with multiple long-lived assets. With some data adjustments, our analysis could probably be applied to data from other market environments like, e.g., experimental data from the continuous double auction, or data from real-world exchanges. The advantage of looking at the call auction in comparison to continuous double auction is that subjects in the call auction can only trade through submission of a limit order to the market. Strategies in the call auction are more similar to another as they require submission of a bid or an offer to sell. In contrast, strategies in the continuous double auction can involve both non-marketable limit orders and market orders. ${ }^{2}$ In the call auction market, investors' reactions to observed market dynamics are recorded once per call so that an investigation of learning dynamics is facilitated. In comparison to the study of real-world data, the controlled laboratory environment has the advantage that we know the exact information and the strategy set of each subject.

The rest of the paper is organized as follows. In Section 2, we introduce our analytical tool excess bids. We formalize competitive hypotheses of adaptive and predictive price formation. In Section 3, we survey the data including a brief description of the experimental data collection method. The main result of that section is that excess bids seems to anticipate subsequent price movements. In Section 4, we discuss adaptive determinants of excess bids. In Section 5, we present testable response modes of learning direction theory, which we subsequently test. Section 6 concludes the paper.

\section{Predictive and adaptive model of excess bids}

\subsection{Excess bids}

To see how investors' behavior changes with the market-phase we work with a proxy for Walras' excess demand. Following Smith et al. (1988), in (1) we define excess bids in market $m$ during period $t$ as the difference in number of submitted bids, $B_{\text {mit }}$, minus offers, $O_{\text {mit }}$ of investor $i$.

$$
X_{\text {mit }}=B_{\text {mit }}-O_{\text {mit }}
$$

In Eq. (2), we account for the asset purchases $P_{\text {mit }}$ and sales $S_{m i t}$, which cancel out on the market level. On the individual level, however, Eq. (1) gives the excess bids before market clearing, and Eq. (2) the remaining excess bids thereafter.

$$
X_{\text {mit }}^{\prime}=\left(B_{\text {mit }}-O_{\text {mit }}\right)-\left(P_{\text {mit }}-S_{\text {mit }}\right)
$$

In terms of notation we denote averages by leaving out an index or two; for instance, $X_{m t}, X_{m}, X$ are averages of excess bids in market $m$ in period $t$, over all periods, or over all markets and periods, respectively.

\subsection{Testable hypotheses and learning direction theory}

For the single unit continuous double auction market (Smith et al., 1988) and single unit call auction market (Van Boening, 1991, 2012) it has been shown that the market excess bids are positively correlated with the price changes of the following period. If the return is positive the excess demand is positive, and vice versa (Plott, 2008a). Asparouhova et al. (2003) investigate the relationship of excess demand and price formation on markets with multiple single-period lived assets, and Plott and Pogorelskiy (2015) investigate multiple demands in double call auctions. Their analysis of excess demand exhausts more information from the data than the excess bids variable does, since they account for the jaws in the order book. The authors report that excess demand is predictive of the within-period price change in their environment. In summary, there is empirical evidence for the predictive quality of excess demand and in particular of excess bids. We contribute to this literature by investigating the predictive success of excess bids in the case of multiple long lived assets. Hence our first testable hypothesis follows.

H 1 (predictive model): The excess bids variable indicates the sign of the excess return of the next period rather than the opposite sign;

$$
r_{m t}^{>} r_{f} \quad \Leftrightarrow \quad X_{m t-1}^{\prime}>_{<}^{>}
$$

where $r_{m t}$ denotes the return on risky security $m$ in period $t$, and $r_{f}$ is the riskfree rate. The return on a risky security is defined as the sum of capital gains yield (left ratio in following equation) and dividend yield;

$$
r_{m t}=\frac{p_{m t}-p_{m t-1}}{p_{m t-1}}+\frac{d_{m t-1}}{p_{m t-1}}
$$

\footnotetext{
2 Plott (2008a) provides a brief but comprehensive review of the results of the growing literature on price formation in double-sided market institutions including the continuous double auction. The continuous double auction is more efficient in capturing the possible gains from trade than the single call market (Cason and Friedman 2008). Nonetheless, as Cason and Friedman report, the efficiency of the call market converges on the one of the double auction with increased call frequency.
} 
where $p_{m t}$ and $d_{m t}$ denote the price and the dividend payment of the risky security at the end of the period, respectively. Dropping the index we average for the market portfolio and across periods. The predictive model suggests that tomorrow's (excess) return is positive if today's excess bids is positive. ${ }^{3}$

In contrast to the predictive model, the adaptive model suggests that tomorrow's excess bids is positive if today's return is positive. In the following section we investigate for how many subjects the excess bids is indicative of the posterior market trend versus the number of subjects whose excess bids follow the market trend (i.e., that the excess bids indicates the pattern of market trend only with hindsight). The literature on price formation has so far considered only the predictive value of excess bids. Since prices in the considered experiments can move in trends, a careful analysis of the excess bids variable requires a test of adaptive adjustment, too.

We investigate this adaptive model of excess bids out of curiosity and to test the predictive model in a meaningful way. Experimental asset market research has suggested that behavior is adaptively adjusted to past observations (e.g. Foresythe et al. 1982, Plott and Sunder, 1982, 1988; Smith et al., 1988; Cason and Friedman, 1997, 1999; Haruvy et al., 2007; Carle et al. 2018). Plott and Sunder (1982) suggest that dissemination and aggregation of information in the market may work with repetition, but learning needs time. Forsythe et al. suggest that subjects swing back on their experiences. Smith et al., Haruvy et al. and also Carle et al. find that prices and expectations converge on fundamentals only with repetition. Cason and Friedman find that some subjects initially under reveal their demand in call markets, but learn to reveal their demand following adaptive dynamics. Adaptation of excess bids has not been reported in the literature before.

The underlying adaptive model applied in Cason and Friedman is called learning direction theory (Selten and Stoecker, 1986; Selten and Buchta, 1999). Learning direction theory, which we apply to response modes in Section 5 to portfolio adjustment, has been quite successful in organizing the experimental data of repeated single-sided markets as well as of other simple experimental settings. Selten (2004) provides a brief literature survey; Goerg et al. (2016) surveys more recent contributions. Learning direction theory generally suggests that after an experienced loss, or a foregone payoff, subjects in the repeated setting adjust their decision in the direction of best response rather than in the opposite direction upon receiving feedback. Interestingly for our case, as we will see below, some studies show that rejected bids in single-sided markets are enhanced in the following repetition in the direction of best response (e.g., Neugebauer and Selten, 2006). Learning direction theory suggests simple, boundedly rational adjustment dynamics that converge in the long run on behavior similar to full rationality (Selten 2004).

In our market environment the feedback variable is excess return. Given a positive excess return, the investor may experience a foregone payoff that he could have earned on a larger long position. Given a negative feedback scenario, i.e., a negative excess return, the investor may experience a loss for holding risky securities that could have been reduced or even avoided on a smaller long position. Foregone payoff and loss condition on short positions point in the same response directions. Applying this concept to our decision variable, excess bids, we state the following testable hypothesis.

H 2 (adaptive model): Individuals increase their excess bids following the positive excess return scenario, $r_{m t}-r_{f}>0$, and reduce their excess bids following the negative excess return scenario ${ }^{4}, r_{m t}-r_{f}<0$;

$$
r_{m t}{ }_{<}^{>} r_{f} \quad \Leftrightarrow \quad X_{m i t+1}>0 .
$$

Again, we denote average market behavior by leaving out the security index $m$ and the time index $t$.

\section{Predictive success of excess bids}

We investigate the predictive and adaptive hypotheses on the market level for (i) the market portfolio and (ii) each security separately. Thereafter, we also look at behavior on the (iii) level of the individual investor.

\subsection{Data}

In 50 interactive trading periods of seven independent market sessions with 20 investor subjects we have gathered a total number of voluntarily submitted offers and bids of 63,221 ; bids (59.25\%) outnumbering offers $(40.75 \%)$. ${ }^{5}$ We observe that on average each individual trader participates in $80.33 \%$ of periods at least in one market and abstains from placing orders in $19.67 \%$ of periods. In $60.08 \%$ of periods, an individual participates on one side of the market as buyer or seller. In $18.15 \%$ of periods, an individual participates in one security. Subjects participate either as buyers or as sellers, but not as both in the same security, in $13.50 \%$ (in two securities) and in $16.79 \%$ (in three securities) of periods. In $11.64 \%$ of periods, individuals try to sell in one market and simultaneously try to buy in another market). In the remaining $20.25 \%$ of participation periods we observe the simultaneous submission of a bid and an offer in at least one market; such bid-offer spreads we observe in

\footnotetext{
${ }^{3}$ If this hypothesis holds, in principle, the investor could possibly capitalize on the excess demand information to speculate on the market turnaround thus reinforcing the hypothesis. Therefore, we emphasize that information on excess demand pattern was unavailable to subjects in the experiment. Note also that the below reported results are quite similar with returns and with capital gains yields only.

${ }^{4}$ The usual relationship (Selten 2004) would involve a weak inequality rather than requesting a strict inequality for the excess demand. However, we disregard in our analysis observations that incur either zero excess demands or zero excess returns.

${ }^{5}$ Our data contain also number of automated bids that result from margin calls. These obviously involuntary orders are not part of this data analysis.
} 


\section{Table 1}

Excess bids and returns.

Relative number of periods with positive or negative excess bids, and periods with positive or negative return. Numbers refer to the individual, single security market, and market portfolio level.

\begin{tabular}{llll}
\hline & Individual $(N=7000)$ & Security $(N=1050)$ & Market portfolio $(N=350)$ \\
\hline \% positive return periods & & 0.7448 & 0.6971 \\
\% negative return periods & & 0.2533 & 0.3029 \\
\% positive excess bid periods & 0.3817 & 0.5905 & 0.6057 \\
\% negative excess bid periods & 0.3209 & 0.3876 & 0.3857 \\
\% zero excess bid periods & 0.2974 & 0.0219 & 0.0086 \\
\hline
\end{tabular}

$7.97 \%, 5.20 \%$ and $7.08 \%$ of periods in one, two or three securities. These numbers are also representative of the individual subject's behavior; $74.29 \%$ of subjects participated in more periods as sellers $(36.22 \%)$ or buyers $(38.06 \%)$ on one market-side rather than on both sides simultaneously $(22.14 \%)$, and three subjects $(2.14 \%)$ were in-between. Two subjects $(1.43 \%)$ did not submit any bid throughout the experiment.

Table 1 reports the relative number of periods with positive and negative excess bids, and positive and negative return. Besides overall data involving 7 sessions, and 3 securities, we report also data on individual decisions (20 subjects per session) from trading in 50 periods (20 investor subjects $\mathrm{x} 50$ periods $\mathrm{x} 7$ sessions). The number of periods with positive asset returns is about three times (75:25 as shown in Table 1) as high as the number of periods with negative returns. Finally, since bids outnumber offers to sell, periods with positive excess bids and periods with negative excess bids behave like 60:40.

Fig. 1 shows the trajectories of average excess bids per security and the average excess return on the market portfolio for each session and period of the experiment. The figure indicates that excess bids and excess returns frequently have the same sign, and signs often repeat from one period to the next.

\subsection{Brief summary of the experimental market design ${ }^{6}$}

Subjects were initially endowed with cash and shares of three securities named L, M, R that carried over from one period to the next. ${ }^{7}$ During each period subjects could trade shares for cash with one another. Margin purchases and short sales of shares were enabled subject to margin requirements. Shares were liquidated after the 50 periods and shareholders received the final book value.

The market organization was a double-sided call auction. Following the individual submissions of sealed bids and offers over 150 seconds (each submission was for one share of a security), the market cleared for each security separately. The clearing mechanism worked as follows. Bids were ranked from high to low and offers from low to high; ties were resolved randomly. The maximum rank for which the bid exceeded or equaled the offer of the same rank determined the transaction quantity, and the bid or the offer of that rank was chosen with equal probability as transaction price. ${ }^{8}$

Dividends and interest payments (the risk free rate on positive cash holdings was $1 \%$ ) were distributed to shareholders following the transactions. Before the next period started, outstanding bids and offers were cancelled.

Throughout the experiment, subjects were given a broad and deep up-to-date record of transaction prices and quantities as well as of their account details. They were always informed on earnings, growth, book value, return including capital gains and dividend yield, and the multiples like price-earnings and price-book value ratios for each security. This is crucial information for the analysis of portfolio adjustment, which we discuss in section 5 .

The experiments were conducted at the EconLab at the University of Bonn; zTree (Fischbacher, 2007) was used for the computer program and ORSEE (Greiner, 2015) for the recruitment of subjects.

\subsection{Excess bids: adaptive vs. predictive model}

Observation 1. The relationship between excess return (over risk free rate) and excess bids is in line with both the adaptive and the predictive model. The predictive model (hypothesis 1 ) has a higher success rate at predicting asset returns than the adaptive model (hypothesis 2).

(i) Market portfolio level analysis: To verify the observation, we count the periods in which the sign of the excess return coincides with the sign of the excess bids variable suggested by the adaptive model and the predictive model, respectively. The result is shown in Table 2. For instance, in session \#1 there are 34 of $49(69 \%)$ periods in which the sign of the excess bid of the adaptive model matches the sign of the excess return, while the predictive model is correct in 40 periods (82\%). On average overall, $69 \%$ and $77 \%$ of the signs of the excessive return are correctly matched by the adaptive and the predictive

\footnotetext{
6 The details of our experimental design (and also of leverage and margin calls) are explained in our companion paper (Selten and Neugebauer 2013). The experimental instructions can be obtained separately from the authors upon request.

7 The securities were independent from each other. For experimental studies with correlated securities, see Charness and Neugebauer (forthcoming).

8 Any price between the last accepted bid and offer can be used for the clearing of the market. With real world markets in mind, where either the bid or the offer is the market price, we implemented this clearing mechanism.
} 


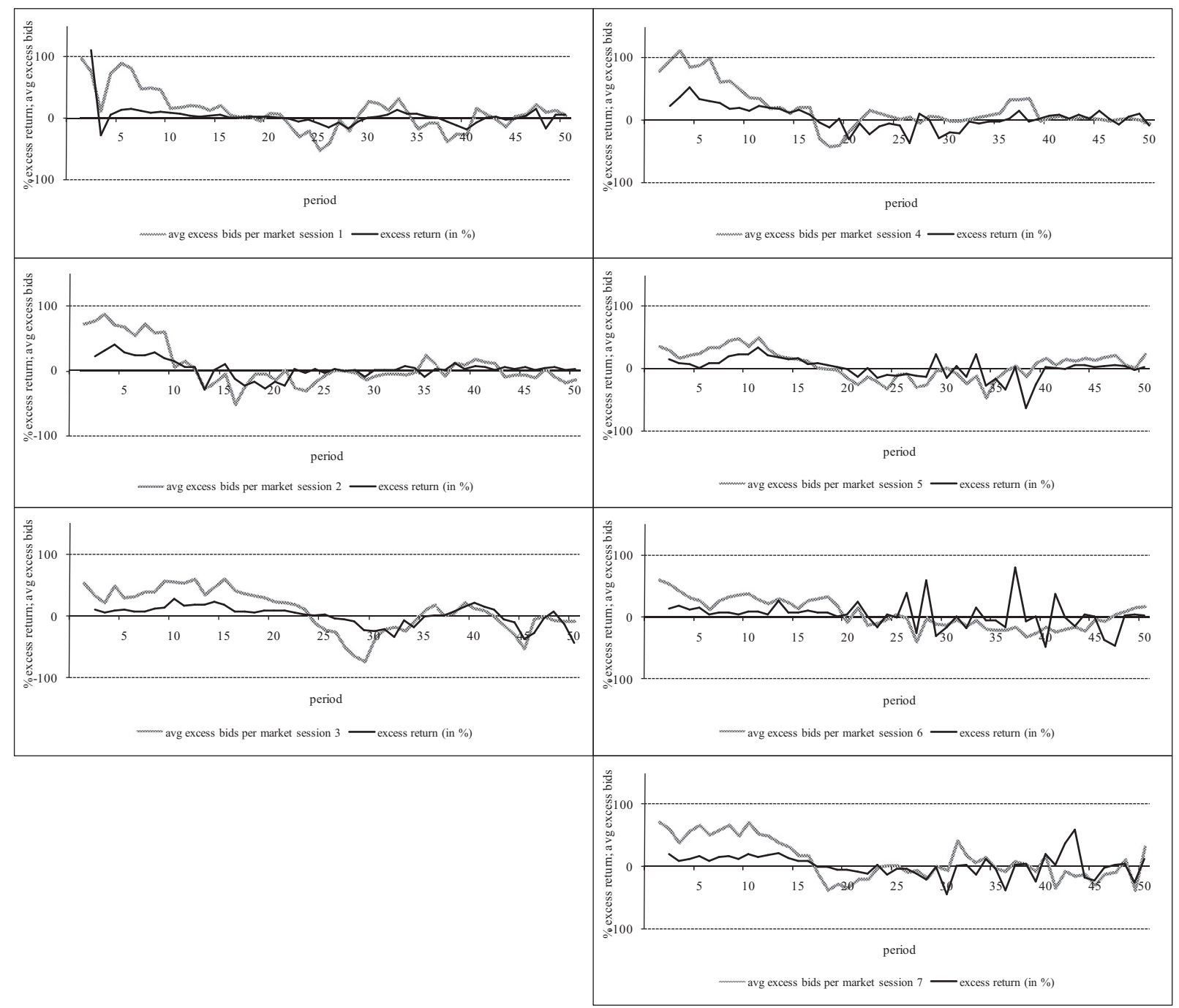

Fig. 1. Excess returns and excess bids.

The figure shows the percentage excess return of the market portfolio $\left(r_{t}-r_{f}\right)$ and the average excess bids per security $\left(X_{t}\right)$ in each period and session of the experiment. Excess return (dark line) and excess bids (grey line) frequently have the same sign and both trajectories involve extensive series of positive and negative signs.

Table 2

Percentage of successful sign matches of excess return and excess bids on market portfolio level (cumulative probability of outcome re random model) [standard deviation across independent sessions].

\begin{tabular}{llll}
\hline Session & $\begin{array}{l}\text { Adaptive model lagged return => sign } \\
\text { of excess bid }\end{array}$ & $\begin{array}{l}\text { Predictive model lagged excess } \\
\text { bid = s sign of return }\end{array}$ & $\begin{array}{l}\text { Random model avg. \% of sign } \\
\text { matches of }\end{array}$ \\
\hline$\# 1$ & $69(0.018)$ & $82(0.000)$ & 54 \\
$\# 2$ & $57(0.096)$ & $63(0.003)$ & 47 \\
$\# 3$ & $82(0.000)$ & $96(0.000)$ & 54 \\
$\# 4$ & $63(0.158)$ & $71(0.008)$ & 53 \\
$\# 5$ & $75(0.001)$ & $83(0.000)$ & 50 \\
$\# 6$ & $71(0.001)$ & $79(0.000)$ & 52 \\
Average & $69(0.011)$ & $65(0.040)$ & 52 \\
[standard deviation] & $69(0.000)$ & $77(0.000)$ & {$[2.78]$} \\
\hline
\end{tabular}


model, respectively. To check the significance of these results, we cannot anticipate that the probability of equal signs is one half. Instead we construct the underlying distribution by repeated simulation. In each simulation, we randomly draw 49 numbers without replacement from the set of periods $\{2,3, \ldots, 50\}$. According to this random sequence of periods we assign the excess bids of the drawn period consecutively to a random sequence. The consecutive random excess bids we denote by, $\tilde{X}_{m i t}$. For instance, if the first drawn random number is 10 , we have $\tilde{X}_{m i 2}=X_{m i 10}$, for subject $i$ in market $m$. For each simulation we compute the number of sign matches, $I_{m i}=\sum_{t=2}^{49} I_{m i t}\left(\tilde{X}_{m i t}\right)$, where

$$
I_{\text {mit }}\left(\tilde{X}_{\text {mit }}\right)= \begin{cases}1, & \operatorname{sign}\left(\tilde{X}_{\text {mit }}\right)=\operatorname{sign}\left(r_{m t}\right) \\ 0, & \text { otherwise }\end{cases}
$$

As described in (6), we compare the sign of the excess return in the period to the sign of the randomly drawn period's sign of excess bid and count the matches. The random model suggests that the response distribution is correct, but that the draws without replacement from that distribution are random. We thus check how probable it is that the excess bids and the excess returns behave in line with the adaptive model vs. the predictive model for given realizations. However, in this paragraph we look at the market portfolio, i.e., $\tilde{X}_{t}, r_{t}$, and not at individual matches. In 10,000 simulations we thus construct the random distribution of successful matches between market-portfolio returns and excess bids for each session. The average matches in the random simulations are reported in Table $2,{ }^{9}$ along with the share of random outcomes that yield at least as many sign matches as proposed by the adaptive and predictive models. In the first session, for instance, 181 of the 10,000 random simulations (0.018) resulted in at least as many matches of excess return and excess bids as the adaptive model, i.e., at least 69\%. The total matches over the seven sessions in each of the 10,000 simulations (including 7 sessions each) fall short of those outcomes yielded by the adaptive and the predictive models as is indicated in the bottom line of the table. ${ }^{10}$ So the data confirm the first part of observation 1 for the market portfolio. The second part is obtained by the one-sample test as the predictive model yields more successful sign matches as the adaptive model in each session but session \#7. According to the Wilcoxon signed-ranks test result, we reject the null hypothesis of an equal number of successful sign matches at the $5 \%$ level of significance; the $p$-value of the two-tailed test is 0.0269 .

In the following presentations, we maintain the notation used in Table 2 reporting standard deviations in brackets and test results in parenthesis, but in order to save space we do not explicitly report the results on session level. In the appendix (A1) we report an extension of the analysis of the observation 1 to security level (ii) and individual investor level (iii). The results confirm observation 1.

Discussion. Excess bids predict future returns in our data. It is particularly striking that the individual subject's excess bids variable is predictive of the market portfolio returns and even of the single security returns. In fact, the described result is not based on subjects' divine intuition but rather on market inertia. The higher the number of rejected sale or purchase orders in the market, the more likely is a price move in the direction of the thinner side of the order book in the next period. If an attempted sale or purchase is rejected this period, it likely leads to a new attempted sale or purchase next period, respectively. This relationship of path dependence of excess bids is investigated and shown in the next section; again on (iv) market level and on ( $v$ ) individual investor level.

\section{Adaptive formation of excess bids}

\subsection{Path dependence of excess bids}

The predictive model performs so well, because excess bids are path-dependent. The lagged rejected excess bids are one major determinant of the submitted excess bids in the following period. In fact, rejected bids and offers are amended, that is, adjusted in the direction of the observed price.

Observation 2. (A) Submitted excess bids highly correlate with the (lagged) rejected excess bids. (The correlation is stronger than with the excess return). (B) Submitted bids are higher and offers to sell are lower than the lagged rejected bids and offers. ${ }^{11}$

(iv) Market portfolio level analysis: We compute the Spearman rank correlation coefficient of the excess bids with the (lagged) excess bids of the prior period for each session. Note that on market portfolio level, the excess bids variable before market clearing highly correlates with the lagged excess bids variable after market clearing. In each session, the correlation coefficient is larger or equal to 0.666 (the maximum being 0.914 ), the average correlation coefficient is 0.785 . The probability that a correlation coefficient of 0.666 or larger happens by chance on 50 period-samples is close to zero according to the Spearman rank correlation test. For ease of comparison, the correlation of the above discussed excess return with the lagged excess bids is on average 0.608 and the [maximum] minimum correlation coefficient is [0.831] 0.385 . $^{12}$ However, the

\footnotetext{
9 The overall simulation average over the 7 sessions is $25.30(52 \%)$ successful matches.

10 To compute the total, we sum the matches over the seven sessions in one random simulation and compare this sum to the observed average of 69 percent and 77 percent of matches of the adaptive and predictive models. The adaptive model and the predictive model beat the random model in each of the 10,000 simulations.

11 Note, our observation of resubmission of amended rejected bids could be related to the observation of Cason and Friedman (1997) that under revelation of demand and supply is curbed with repetition.

12 Presuming independence, a correlation coefficient of .385 still would be significantly larger than zero at the $5 \%$ significance level according to the Spearman rank correlation test, $\mathrm{p}=.006$.
} 
Table 3

Average Spearman rank correlation coefficient of individual excess bids and lagged individual excess bids and lagged individual excess bids and market excess return [standard deviation across independent sessions].

\begin{tabular}{lll}
\hline & $\begin{array}{l}\text { Lagged rejected excess bids and } \\
\text { submitted excess bids }\end{array}$ & $\begin{array}{l}\text { Lagged rejected excess bids and } \\
\text { subsequent excess return }\end{array}$ \\
\hline Average Rho asset L & 0.580 & 0.376 \\
Average Rho M & {$[0.055]$} & {$[0.053]$} \\
Average Rho R & 0.585 & 0.340 \\
Average Rho sum & {$[0.041]$} & {$[0.084]$} \\
& 0.585 & 0.356 \\
& {$[0.080]$} & {$[0.090]$} \\
& {$[0.069]$} & 0.388 \\
\hline
\end{tabular}

correlation coefficient of the excess bids with the lagged excess bids is larger than the latter in each session. The correlation coefficients are thus significantly different at the five percent level, the $p$-value of the two-tailed Wilcoxon signed ranks test is $0.018 .{ }^{13}$ These results support the observation $2(\mathrm{~A})$ on market portfolio level.

(v) Individual investor level analysis: For each subject we compute the Spearman rank correlation coefficient of lagged excess bids variable after market clearing, $X_{m i t-1}^{\prime}$, and excess bids variable before market clearing, $X_{\text {mit }}$, over all periods. We compute the individual's correlation coefficients of excess bids and lagged excess bids for each security and for the sum across all three assets. For ease of comparison, we also compute for each individual the correlation coefficients between lagged excess bids after market closing and the excess return in the corresponding market and overall. Table 3 records the average individual Spearman rank correlation coefficients on asset level and on market portfolio level. To test for differences between the two correlation measure approaches we aggregate on independent session level, $N=7$. We find that the average correlation coefficient between the excess bids variable and the lagged rejected excess bids variable is larger than the correlation with the excess return for each session, on asset level as well as on market portfolio level. According to the two-tailed Wilcoxon signed ranks test, the $p$-values are 0.018 on each security level and on market portfolio level, thus supporting observation $2(\mathrm{~A})$.

In support of observation 2(B), we find that individuals adjust their lagged rejected bids and offers in the direction of the lagged price rather than in the opposite direction. For each subject we compare the highest [lowest] submitted bid [offer] to the lagged highest [lowest] rejected bid [offer]. In this analysis we consider consecutive periods of order submission to the same market. We count the number of times that the rejected bid [offer] is increased [decreased], maintained, or decreased [increased]. Overall, 67\% of individual submitted orders enhance the lagged rejected orders in the direction of the price and are thus in line with the adaptive rule, $15 \%$ are unchanged, and $18 \%$ are opposing the rule. Only two subjects of 140 violate the adaptive rule more often than confirming it. However, if "unchanged" is counted as confirmation as Selten and Buchta (1999) accept, all subjects behave in line with the adaptive enhancement rule. Hence, we find overwhelming support in favor of observation 2(B).

\subsection{Adjustment to observed prices}

The excess bids variable adjusts adaptively to the observed price level. If the price level is [high] low, the excess bids variable is [low] high in our data. The fundamental law that the demand decreases and supply increases with price (Marshall, 1890) is a global driver of market behavior. ${ }^{14}$ Importantly, we observe rather an adaptive fundamental law of excess bids rather than an immediate response. Excess bids react to observed price levels. The analysis is performed on market portfolio level and on security level.

Observation 3. Submitted excess bids inversely correlate with observed (i.e., lagged) price levels. (The correlation is stronger than with current and subsequent price levels).

(vi) Data analysis: In Table 4 we report the average correlation coefficients across our independent sessions. The first three rows display the aggregate session results on security level and the last row those of the market portfolio. The Spearman rank correlation coefficients between the excess bids variable and the lagged price are rather large and negative. The negative correlation indicates that bids outnumber offers to sell for small price levels and vice versa. For ease of comparison we also report the correlation coefficients of excess bids with the prices in the same period. These correlation coefficients are negative too. However, the size of the correlation is significantly smaller; they are smaller for each security in each session. The probability that such an extreme difference happens by chance is 0.018 . The excess bids and next period prices are also negatively correlated, but the size of the correlation coefficient is for each session smaller than those of the (same

\footnotetext{
13 Note the average correlation coefficient of excess return and lagged excess return is .483 . Both reported correlations with the excess bids, however, are larger for each session.

14 Asparouhova, Bossaerts and Ledyard (2016) discuss both Walrasian and Marshallian dynamics of experimental markets (see also Plott 2008b).
} 
Table 4

Average Spearman rank correlation coefficient of the excess bids variable with lagged price and with the same period price (two-tailed Wilcoxon signed ranks test result of zero correlation) [standard deviation across independent sessions].

\begin{tabular}{lll}
\hline & Excess bids and lagged price & Excess bids and (same period) price \\
\hline Average Rho asset $\mathrm{L}$ & $-0.360(0.028)$ & $-0.239(0.028)$ \\
& {$[0.228]$} & {$[0.204]$} \\
Average Rho M & $-0.392(0.018)$ & $-0.259(0.028)$ \\
& {$[0.234]$} & {$[0.256]$} \\
Average Rho R & $-0.419(0.018)$ & $-0.247(0.028)$ \\
Average Rho Portfolio & {$[0.150]$} & {$[0.172]$} \\
& $-0.397(0.018)$ & $-0.288(0.018)$ \\
& {$[0.214]$} & {$[0.218]$} \\
\hline
\end{tabular}

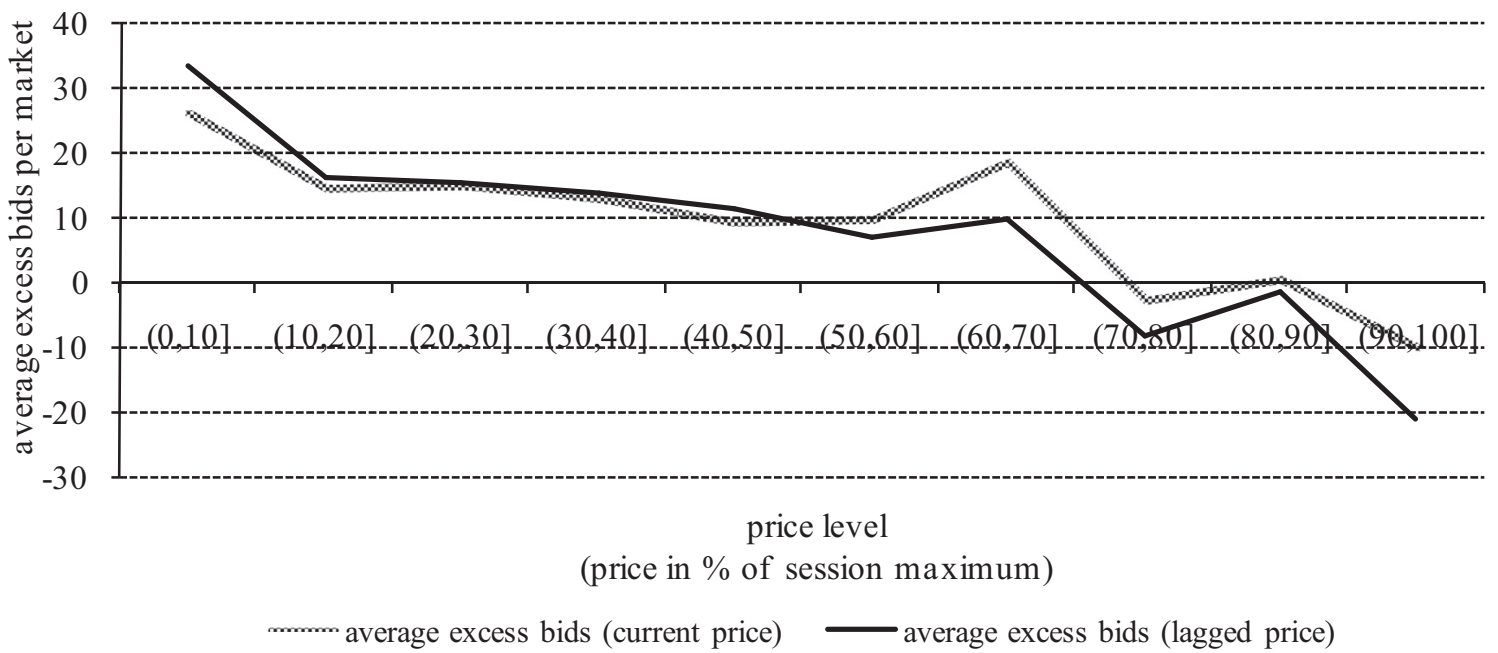

Fig. 2. Average excess bids and (current and lagged) prices.

The figure shows excess demand as decreasing function of price level. Price levels are organized in ten-percent intervals relative to the record-high security price. The figure shows the corresponding average excess bids per security. The lagged-price excess-bids curve is steeper than the current-price curve; lagged-price excess bids are larger than current-price excess bids below the 50 -percent price level and vice versa.

period) price. Thus, we conclude that the correlation of excess bids and lagged price indicates causality, and thus reinforces our proposition of adaptive formation of excess bids.

Fig. 2 shows the relationship described in observation 3 of excess bids and (current and lagged) price levels on security average. For each security we take the price at record high to scale the observed prices in that security from 0 to $100 \%$. We aggregate the average excess bids over ten percent intervals. The interval $(50,60]$, for instance, contains the average excess bids for all prices larger than $50 \%$ and at most $60 \%$ of the record high. The current price is observed in the same period as the excess bids, and the lagged price is observed in the previous period, i.e., immediately prior to order submission. The relatively steep curve indicates the strong response of the excess bids to observed lagged prices. A similar but less steep declining pattern is indicated for the curve of current prices. Excess bids are close to zero around 70\% of the security's record high price when considering lagged prices, and between 70 and $90 \%$ when considering current prices.

To complete the picture of aggregate dynamics we conduct a linear regression of excess bids on lagged prices and lagged excess bids with session clusters. We report the regression on market-portfolio level. Similar results are achieved on the security level. The determination coefficient of 0.730 indicates the goodness of fit. Asterisks indicate significant results; ${ }^{* * *} p<.01 ;{ }^{* *} p<0.05$ (t-stats are reported in parenthesis).

$$
X_{t}=\underset{(3.86)}{811^{* * *}}+\underset{(23.75)}{789} X_{t-1}^{\prime * * *}-\underset{(-2.70)}{.002} p_{t-1}^{* *}, \quad R^{2}=.730, N=343,7 \text { clusters }
$$

In summary, the predictive power of excess bids does not come over investor subjects through divine inspiration but it is implied by the market forces. Excess bids behave adaptively, as response to observation. Excess bids adaptively respond to rejected excess bids thus reinforce the price motion, and excess bids respond to the observed price level thus attracting the price motion to fundamentals. In this way, excess bids shape the market interactions. 


\section{Portfolio adjustments}

Investors categorize assets into classes like large cap, value, or growth stock. Such classes are frequently called styles, and the process of allocation of funds among styles is called style investment (Barberis and Shleifer, 2003). In this section the investment style approach is integrated as response mode in learning direction theory (Selten, 2004). We focus on adaptive style-investment where funds are shifted within one style. Investors allocate funds based on relative past performance, moving into the security category (e.g., high book to market) that ranked high in the recent past and moving out of the security category (e.g., low book to market) that ranked low. We are first to propose this (complex) application of learning direction theory (Selten, 2004) to portfolio adjustments in experimental data.

\subsection{Adaptive models of investment style}

\subsubsection{Path dependence}

In the multi-security environment, the portfolio of the investor is readjusted with each purchase or sale. In this section we investigate strategies of portfolio adjustments. Above we have reported that the excess bids in our data are adaptively determined. In finance jargon, we could say excess bids are momentum-driven. Subjects reinforce the market trend by "reentering" enhanced rejected excess bids. In line with the above reported observations we define our first strategy for the multi-asset environment by path dependence of the excess bids;

$$
\text { PATH : } \hat{X}_{m_{1} i t} \geq \hat{X}_{m_{2} i t} \geq \hat{X}_{m_{3} i t} \Leftrightarrow X_{m_{1} i t-1}^{\prime} \geq X_{m_{2} i t-1}^{\prime} \geq X_{m_{3} i t-1}^{\prime}
$$

where $m_{1}, m_{2}, m_{3}=\{L, M, R\}$ denote the three security markets and the hat indicates the ranks high, middle, and low of the excess bids variable predicted by the adaptive model. According to PATH, the predicted ranks of the individual excess bids coincide with the prior ranks of the excess bids after market clearing.

\subsubsection{Response mode: momentum ${ }^{15}$}

The following adjustment model involves momentum as adaptive response mode, which (other than the PATH model) is linked to ranks of the recent security returns. This response mode of portfolio adjustment is in line with learning direction theory. In this response mode and also in the alternative response modes discussed below, the excess bids variable adaptively adjusts in the direction of the ex-post best response. Thus, we define momentum-style investing (MOM) as an investment strategy that puts more weight on the security that has yielded a high return in the latest period and underweight the security that has yielded the low return.

$$
\text { MOM : } \hat{X}_{m_{1} i t} \geq \hat{X}_{m_{2} i t} \geq \hat{X}_{m_{3} i t} \Leftrightarrow r_{m_{1} t-1}>r_{m_{2} t-1}>r_{m_{3} t-1}
$$

The momentum style (9) proposes that the individual excess bids in the period will be ranked according to the return ranks of the assets in the last period. ${ }^{16}$ MOM puts overweight the security with the lagged high-return rank and underweight the asset with the lagged low-return rank.

\subsubsection{Response mode: size}

The momentum style identifies excess return ranks with the securities $L, M, R$ themselves. There are alternative response modes of learning direction theory for portfolio choice. Investors may identify the excess return impulses with other qualities of the security rather than with its name.

We define size-style investing (SIZE) as the adaptive response mode that ranks the prior company-sizes (i.e., market capitalizations) according to their return in the latest period, and accordingly adjusts the excess bids on the current companysizes. Let $\left[p_{1 t-1}\right],\left[p_{2 t-1}\right],\left[p_{3 t-1}\right]$ denote the three size ranks of the securities at the beginning of the prior period, ${ }^{17}$ where the index $\{1,2,3\}$ indicates the prior return rank, that is, the return rank of the prior period, $r_{\left[p_{1 t-1}\right] t-1}>r_{\left[p_{2 t-1}\right] t-1}>r_{\left[p_{3 t-1}\right] t-1}$. The corresponding size ranks of this period before the return of the current period is revealed are denoted $\left[p_{1 t}\right],\left[p_{2 t}\right],\left[p_{3 t}\right]$, where the index $\{1,2,3\}$ again indicates the prior return rank. So the adaptive investor ranks the security by market capitalization and implies excess-bid submissions in line with the prior return rank. The size-style response mode implies the following adaptive behavior.

$$
\text { SIZE : } \hat{X}_{\left[p_{1 t}\right] i t} \geq \hat{X}_{\left[p_{2 t}\right] \text { it }} \geq \hat{X}_{\left[p_{3 t}\right] \text { it }} \Leftrightarrow r_{\left[p_{1 t-1}\right] t-1}>r_{\left[p_{2 t-1}\right] t-1}>r_{\left[p_{3 t-1}\right] t-1}
$$

The size-style response mode generally proposes a different ranking of securities and thus a different excess-bids variable than the momentum-style response mode. Nonetheless, the excess bids of both response modes can coincide in particular periods depending on the changes in the rankings of the underlying securities from the prior period.

\footnotetext{
${ }^{15}$ Indeed there is abundant evidence of related adaptive behaviors in financial real-world markets. Momentum effects are widely known; short-term winning stocks outperform short-term losing stocks over the following six-month time horizon. Evidence suggests a long-term reversal, since long-term losing stocks outperform long-term winning stocks over the following years. (For a literature survey see Barberis and Thaler 2003). Considering flows into and out of mutual funds also shows that funds investors are strongly affected by lagged measures of excess returns, despite the fact that the relative performance of mutual fund managers appears to be largely unpredictable from past relative performance (Berk and Green 2004).

${ }^{16}$ If the subject's strategy is to adjust the investment weights rather in the opposing direction, we could talk about contrarian momentum-style investing. Since both MOM and the contrarian strategy yield similar results in our data analysis, i.e., they do not perform too well, we skip the latter one.

${ }^{17}$ Note the price of the company fully reveals its market capitalization in our experimental environment.
} 

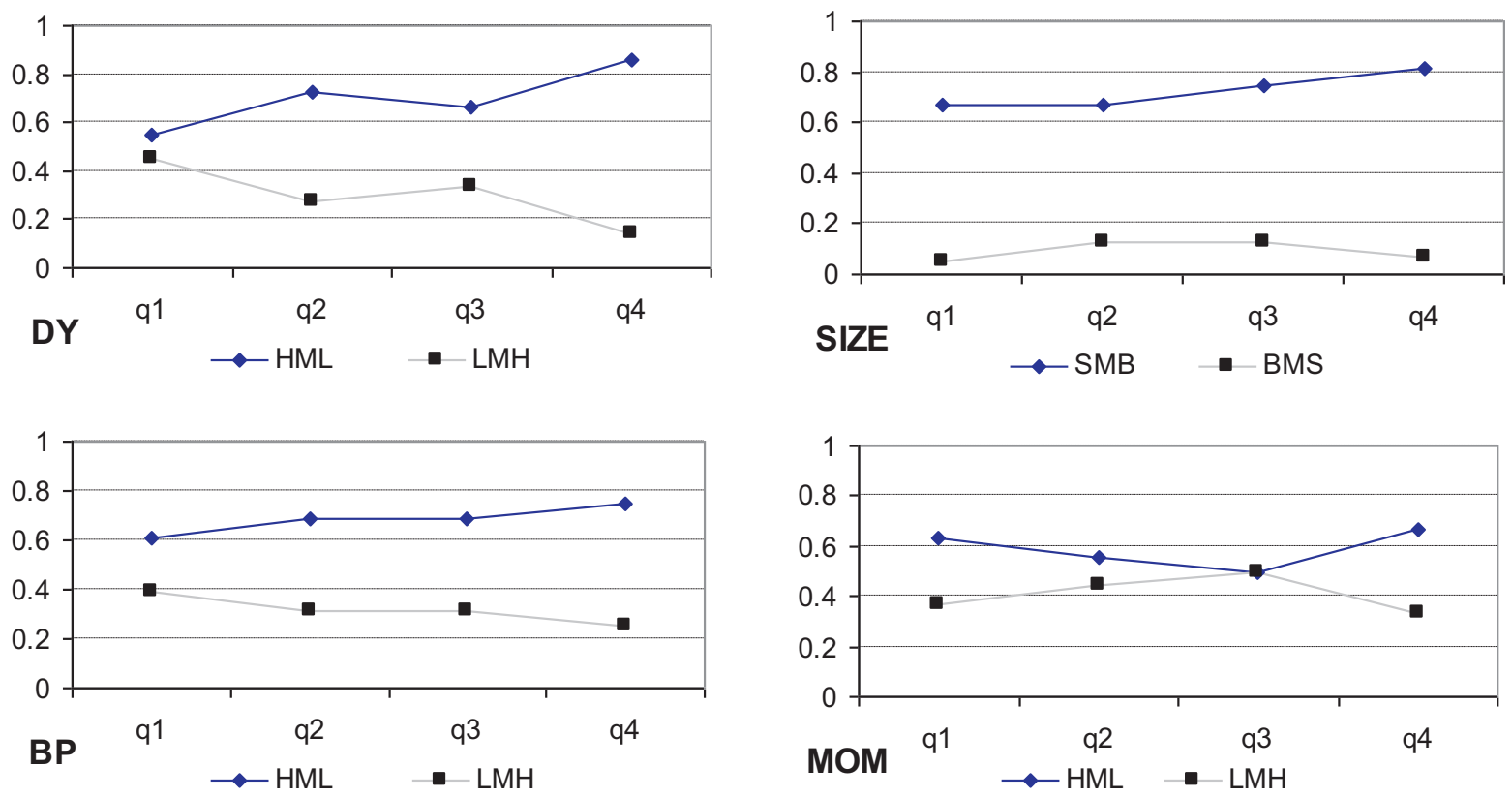

Fig. 3. Evolution of market strategies (overweight and underweight securities).

For example, if the intermediate-size company ranks high on return, i.e., higher than the small-size and the large-size company. The return-ranks of the intermediate-size and the large-size company in the prior period are high and low, $\left[p_{1 t-1}\right]$ and $\left[p_{3 t-1}\right]$. The adaptive investor's excess bids variable of the current intermediate-size company will therefore rather be larger than of the current large-size company. In this example it could happen that after the latest return the prior intermediate-size company becomes the current large-size company. The highest excess bids would then be placed on the prior large-size company, which would then be the current intermediate-size company (if the small company stays with its size rank).

Note the difference to size-style investing "small minus big - SMB" suggested in the finance literature. This well-known static investing-style suggests go long the cross section of small-cap stocks and short the large-cap stocks.

\subsubsection{Response modes book-to-price and dividend-to-price ratios}

Instead of examining company size, the response mode may rather incorporate the price-value relationship in the underlying security. The value-style response modes require a prior return-ranking, that is, the ranking of the prior excess returns on the high-, middle-, and low value security, where security value is measured by the multiples of book value (in our case equivalent to replacement cost) or earnings (in our case equivalent to dividends). The value-style response modes next require a ranking of the securities based on the current value of the securities. Finally in line with learning direction theory, the excess bids are adjusted in the direction of the prior return-ranking. We define value-style investing in the following two equations. Eq. (11) involves the dividend yield (or earnings to market) as the measure of focus, and Eq. (12) the book-to-price multiple; $b_{m t}$ denotes the current book value per share or replacement cost of asset $m .^{18}$

$$
\begin{array}{ll}
\text { DY : } & \hat{X}_{\left[d_{1 t-1} / p_{1 t}\right] i t} \geq \hat{X}_{\left[d_{2 t-1} / p_{2 t}\right]} \geq \hat{X}_{\left[d_{3 t-1} / p_{3 t}\right] i t} \Leftrightarrow r_{\left[d_{1 t-2} / p_{1 t-1}\right] t-1}>r_{\left[d_{2 t-2} / p_{2 t-1}\right] t-1}>r_{\left[d_{3 t-2} / p_{3 t-1}\right] t-1} \\
\text { BP : } \quad & \hat{X}_{\left[b_{1 t} / p_{1 t}\right]} \geq \hat{X}_{\left[b_{2 t} / p_{2 t}\right] i t} \geq \hat{X}_{\left[b_{3 t} / p_{3 t}\right] i t} \Leftrightarrow r_{\left[b_{1 t-1} / p_{1 t-1}\right] t-1}>r_{\left[b_{2 t-1} / p_{2 t-1}\right] t-1}>r_{\left[b_{3 t-1} / p_{3 t-1}\right] t-1}
\end{array}
$$

By $\left[d_{1 t-1} / p_{1 t}\right],\left[d_{2 t-1} / p_{2 t}\right],\left[d_{3 t-1} / p_{3 t}\right]$ and $\left[b_{1 t} / p_{1 t}\right],\left[b_{2 t} / p_{2 t}\right]$, $\left[b_{3 t} / p_{3 t}\right]$ we denote the three ranks of dividend yield and book-to-price ratio at the beginning of the current period, respectively. ${ }^{19}$

For example, assume the prior period's return implies the following prior book-to-price value-ranking; the prior high book-to-price security yielded the lowest return and is therefore indexed $3,\left[b_{3 t-1} / p_{3 t-1}\right]$, the prior intermediate-value asset yielded the high return $\left[b_{1 t-1} / p_{1 t-1}\right]$, and the return of the prior low book-to-price security ranks in-between $\left[b_{2 t-1} / p_{2 t-1}\right]$. According to (12), the current excess-bids vector puts overweight on the current intermediate-value and underweight on

\footnotetext{
${ }^{18}$ We also looked at earnings growth as another alternative adaptive model to find a lower success rate than with the dividend-yield model and the book-price model. Therefore, we skip the report.

${ }^{19}$ We remind the reader that the dividend is paid out at the end of the period, after price determination and market clearing. So, we have this slightly unfortunate notation accounting for our experimental design.
} 
Table 5

Success rate of adaptive models compared to random simulation distribution. The success rate is the number of ranks matches between the models and observed excess bids. The models are defined in Eqs. (8)-(12).

\begin{tabular}{ll}
\hline Adaptive model & $\begin{array}{l}\text { Share of subjects with success rate in top-five } \\
\text { percentile of random model distribution }\end{array}$ \\
\hline BP & 0.79 \\
PATH & 0.78 \\
DY & 0.69 \\
SIZE & 0.64 \\
MOM & 0.62 \\
\hline
\end{tabular}

the current high-value security. ${ }^{20}$ Without value-ranks-changes between periods, our adaptive strategies SIZE, DY, BP and MOM possibly predict identical excess-bids rankings. If the value ranks change between periods, however, the predicted excess-bids rankings can significantly diverge.

\subsection{Method of measuring success rate and results}

Based on each of the described adaptive models, we make predictions of excess bids ranks for the periods 3-50 on the basis of our observations for periods 2-49. For instance, if the L security is ranked high in MOM and the M security is ranked low, the prediction assigns the rank 1 to L, 2 to $\mathrm{R}$ and 3 to the $\mathrm{M}$. The observed individual excess bid ranks in the period is compared to the predicted rank; each match of any rank counts one, mismatches count zero. ${ }^{21}$

$$
I_{m i t}= \begin{cases}1 & \text { if } X_{m i t}=\hat{X}_{m t} \\ 0 & \text { otherwise }\end{cases}
$$

If no ranking is possible because either all predicted ranks are zero (in case of no transaction or identical returns), or all observed ranks are zero (in case of same excess bids variable in each security), the period is neglected. We compute matches of ranked excess bids with the ranked predictions of our adaptive models PATH, MOM, SIZE, DY and BP for each period. The models' success rate is the total for each subject, $I_{i}$. To evaluate the observed success rates we construct for each subject a test distribution again by a random model. We independently draw the simulated predicted ranks of the 3 companies without replacement from the set $\{1,2,3\} .^{22}$ For each period and each subject, the random model success rate is the total number of matches between the ranks of the subject's excess bids and the simulated predicted ranks over periods 3 to 50. The simulated distribution is constructed by computing 10,000 random success rates for each subject. The following observations are based on the comparison between the distribution of random success rates and the observed individual success rate of our adaptive models.

Observation 4. The adaptive models BP, PATH, DY, SIZE, MOM jointly achieve a success rate in the top 5 percentile of the simulated distribution of random success rates for more than $95 \%$ of individuals.

(vii) Data analysis: In Table 5 we report the share of subjects for whom the adaptive models' success rate exceeds at least $95 \%$ of the simulated random success rates. These shares are partially overlapping. Hence, for more than $95 \%$ of subjects we have at least one model with a success rate in the top-5\% of the simulated random success rates or higher. ${ }^{23}$

Observation 5. The success rate of BP and PATH is larger than of MOM, DY and SIZE.

(viii) Data analysis: To statistically compare the goodness of fit of our adaptive models, we aggregate the success rates of each model for each independent session. Based on the measurements from the seven independent sessions per model, we statistically support observation 5 . The two-tailed Wilcoxon signed ranks test indicates significant differences between the success rates of BP and PATH and DY ( $p$-value of 0.091 and 0.043), SIZE ( $p$-value of 0.043 and 0.063), and MOM ( $p$-value of 0.018 each), respectively. The differences between DY and MOM ( $p$-value of 0.018 ) are significant, too.

Observation 6. (Robustness test) The performance of the adaptive models BP, DY, SIZE and PATH remains significant when the simulation involves the reshuffling of (individually observed) success rates. The goodness of fit of the adaptive models BP, DY and PATH is higher than of their static and predictive pendants. See the data analysis in appendix (A2).

Observation 7. The individual payoff is correlated to the individual success rate of the adaptive models BP and DY.

\footnotetext{
${ }^{20}$ In this example, in fact, the former high-value security will be identical to the current high-value asset unless the current earnings would be inferior to the other companies. Nonetheless, due to price appreciation (and poor earnings) the prior intermediate-value asset may evolve to become the current low-value asset.

${ }^{21}$ For example, if the adpative model predicts the ranking of the securities LRM, and the realized individual's excess bids ranks MRL (i.e. ranks M at 1, $R$ at 2 and $\mathrm{L}$ at 3 ). $\mathrm{R}$ is thus second in both rankings, and there are two mismatches. Therefore, we would count one match for this example period.

${ }^{22}$ We also simulated ranks with replacement. Since the success rate is worse than of the simulation without replacement, we skip the discussion of the results.

${ }^{23}$ Another 3 subjects' data have a success rate between 90\% and 95\% with one or more of our models, for one subject we find only one model's success rate exceeding $75 \%$ of the simulated random success rates. As reported above two subjects do not submit orders along the experiment.
} 
(x) Data analysis: Since observation 4 shows that subjects' behavior in form of the ranks on their excess bids can be approached by our adaptive models, we find it interesting to check for correlations between individual earnings and adaptive type. Taking the number of random success rates that exceed the observed success rates as a proxy for the goodness of fit of the individual data, we measure the correlation of this proxy with the subject's final payoff. Excluding subjects with negative payoffs, we find the largest Spearman rank correlation coefficients of 0.2027 and 0.2017 for BP and DY (N=117), respectively. Larger sizes of correlation coefficients are obtained only when the static BP and DY models (sell high, buy low) are used; the correlation coefficients are 0.2261 and 0.2733 , respectively. These coefficients and their sign seem to indicate that subjects whose excess-bids ranks qualify for value-style investing outperform other subjects on payoff. This evidence seems to suggest that (adaptive and static) value-style investors outperform the market in our experiment.

\subsection{Time varying weights of adaptive models}

Finally, Fig. 3 shows the evolution of market ranks over four quarters of the experiment, involving periods 3-14, 15-26, 27-38, and 39-50, respectively. For the ease of presentation we leave out the intermediate model rank. The first letter in the legend of the charts shows the overweight position, the last letter the underweight position. For the SIZE model, BMS reads "big minus small" and SMB vice versa. For the MOM and the value models, HMS reads "high minus low", LMH "low minus high". For DY and BP, HML involves overweight the high value and underweight the low value. From the charts we get the impression that markets move toward the static models suggested above. The trajectories start above average and move towards the extremes indicating that static value-style investing gradually emerges as principal strategy. Excess-bids ranks in DY and PB move towards HML (buy high value, sell low value), and SIZE moves towards SMB (buy small, sell big). HML (buy high momentum, sell low momentum) also seems to be an important strategy within MOM, but we see no clear dynamic pattern over time.

\section{Conclusions}

In the paper we have investigated the dynamics of the excess bids variable which is considered as a proxy for Walrasian excess demand. Initially we find that the excess bids variable seems to be predictive of price changes, thereby confirming results of other studies (Smith et al., 1988; Van Boening, 1991, 2012). Even for the individual investor data, we find similar evidence. When we examine the determinants, all data points favor an adaptive formation of excess bids. In our study we have identified two adaptive market forces that seem to account for the formation of excess bids. Firstly, we observe a pathdependence of excess bids; subjects reinforce the market trend as they "re-enter" enhanced rejected excess bids at market opening. Secondly and frequently opposing the trend, we have noticed Marshallian dynamics (Asparouhova et al., 2016) in our data. The fundamentals affect a lowering of excess bids with an increase in the price level, and vice versa. The detected fundamental dynamics in our data are also adaptive; the excess bids respond to lagged price levels rather than to anticipate price levels. Excess bids decrease (because investors submit more sale offers) following the observation of a high price level.

The most important contribution of the paper is the proposed application of learning direction theory (Selten and Stoecker, 1986; Selten, 2004) to complex, multi-dimensional decision problems and use learning direction theory for selection between different learning modes. In the received literature, learning direction theory has shown to capture the behavioral dynamics of many one-dimensional decision problems. ${ }^{24}$ We have proposed learning direction theory in the framework of investing style models (Barberis and Shleifer, 2003) to study adaptive portfolio adjustment behavior in an environment with multiple dimensions of decision making. The adaptive models of style investing jointly describe the excess bids ranks of almost all subjects significantly better than chance. Static versions of these investment styles, like "high minus low" or "small minus big", are well-known on Wallstreet. Our laboratory subjects, however, are rather unfamiliar with investment models. In fact, when we compare our adaptive models to their static pendants we find significantly higher success rates at matching observed choices with the adaptive models than with the static models. Nonetheless, with repetition the trajectories of observed excess bids move in the direction of the static models. This evidence shows that static investment style models evolve through individual learning in our market environment. Comparing success rates between styles, our data show strongest indication of adaptive value-style investing and also the model of path-dependence of excess bids receives strong support. Thus we have shown how learning direction theory can be applied in a complex environment involving multiple response modes. We also suggested that through the goodness of fit analysis one can select between different response modes to explain market behavior. In our market environment, behavior is described by the response mode value-style investing rather than momentum-style investing.

Learning direction theory can be applied to other simple or complex environments. We believe that the insights from our study offer valuable information to researchers who do data mining in search of real-world evidence or agent based modeling of market behavior. ${ }^{25}$

\footnotetext{
24 Selten (2004) summarizes earlier contributions to learning direction theory; Goerg, Neugebauer, Sadrieh (2016) summarize more recent contributions. 25 Recent evidence from U.S. equity markets showing that trading volume increases with lagged returns (Statman, Thorley, and Vorkink 2006) may be related to our adaptive fundamental excess demand dynamics. In a recent paper, Hommes and Lux (2013) have shown using agent based modeling that adaptive behavior can explain individual and aggregate market behavior.
} 


\section{Table 2S}

Percentage of successful sign matches of excess return and excess bids (cumulative probability of outcome re simulation model) [standard deviation across independent sessions].

\begin{tabular}{llll}
\hline & Adaptive model & Predictive model & Simulation model \\
\hline Average asset L & $70(0.000)$ & $77(0.000)$ & 56 \\
& {$[4.47]$} & {$[10.49]$} & {$[5.80]$} \\
Average asset $\mathrm{M}$ & $67(0.000)$ & $74(0.000)$ & 52 \\
& {$[8.00]$} & {$[10.41]$} & {$[3.47]$} \\
Average asset $\mathrm{R}$ & $66(0.000)$ & $74(0.000)$ & 52 \\
Average asset sum & {$[13.56]$} & {$[8.78]$} & {$[3.15]$} \\
& $67(0.000)$ & $75(0.000)$ & 53 \\
& {$[5.91]$} & {$[7.95]$} & {$[3.42]$} \\
\hline
\end{tabular}

So far we have investigated directional learning dynamics in a call-auction market with periodical clearing and price revelation. The next logical step is to extend our analysis to continuous market clearing, and try to reproduce the reported results in the more standard double-auction market. Compared to the continuous double-auction market, we imagine that the analyzed call-auction dynamics are rather slow, orderly structured and less noisy.

\section{Appendix}

(ii) Security level analysis (observation 1): As discussed above; the market portfolio consists of three different risky assets. The analysis under $(i)$ is basically repeated for each security, i.e., $\tilde{X}_{m t}, r_{m t}$. The outcome is very similar; the adaptive model and the predictive model outperform the "random model" for most sessions but not for all sessions. The average matches of excess return and excess bids over the seven sessions are reported in Table 2S. The adaptive model yields an average match of $67 \%$ and the predictive model $75 \%$, whereas the random model $53 \%$. The differences between the adaptive model and the predictive model are again significant at the 5-percent level; according to the two-tailed Wilcoxon signed-ranks test, the probability value of the sum of matches in the three security markets of the session is $0.0277 .^{26}$ So we confirm observation 1 on the security level, too.

(iii) Individual investor level analysis (observation 1): To conduct the analysis, we count the number of subjects whose observed behavior is in line rather than in disagreement with the adaptive model and the predictive model, respectively. ${ }^{27}$ We apply the following analysis. First we count the number of periods with sign matches, $I_{\text {mit }}$, of excess return and excess bids in line with the adaptive and predictive model and the number of sign mismatches, respectively. Periods of zero excess bids are removed from the analysis. ${ }^{28}$ The sign matches exceed the sign mismatches for the majority of subjects; i.e., for $89 \%$ applying the adaptive model, and for $91 \%$ applying the predictive model as shown in Table 2I. For this task, we have counted the number of subjects in each session that behave in line with the model, and compare the number across predictive and adaptive model by session. The number of subjects is not significantly different for both the predictive and the adaptive model; the two-tailed Wilcoxon signed ranks test suggests a $p$-value of 0.7977 . However, accounting for the average excess number of model matches over the number of mismatches on session level we find that the average excess number in line with the predictive model is larger than the one in line with the adaptive model; according to the two-tailed Wilcoxon signed ranks test, the probability value is 0.063 . The test result is obtained on seven observations on the session averages of subjects' total matches under the adaptive model and under the predictive model. Finally, we check the adaptive model and the predictive model for each security on the investor level. The pattern of sign matches of excess return and excess bids in line with our models is confirmed for the majority of subjects for each security; see Table 2I for the results of the two-tailed Wilcoxon signed ranks test of the null hypothesis that investors who match excess return and excess bids in line with our models are as frequent as mismatching investors. As shown in the table, the percentage of subjects in line with the predictive model is larger in every security than in line with the adaptive model; however, it is only significantly larger in the $\mathrm{R}$ security for which the two-tailed Wilcoxon signed ranks test suggests a $p$-value of 0.0473 ( $p$-values for $\mathrm{L}$ and $\mathrm{M}$ securities are 0.3508 and 0.1755 ). Again the between-model comparison on the session averages of individual excess matches favors the predictive model over the adaptive model; the $p$-values of the Wilcoxon signed ranks test are 0.0425 , $0.1282,0.0280$ for the assets L, M, and R, respectively. In summary, our data provide overwhelming evidence in support of observation 1 , from the aggregate level to the individual level.

\footnotetext{
26 The test on the security level yields the following probability values; .0277, .1071, and .0340 for asset L, M, and R, respectively. For each asset and overall three assets, the adaptive model yields in at least one session a larger number of matches than the predictive model of excess returns.

27 Alternatively, counting the number of matches on individual excess bids and aggregating the number of matches on the session level would lead to the same conclusions.

28 The analysis verifies the number of subjects whose data are in line with each model. The data of those subjects whose total excess bids variable is zero are removed from the analysis. Thus, depending on the analysis $2 \%$ to $4 \%$ of data points are eliminated. The denominator of the reported proportions is reduced accordingly.
} 


\section{Table 2I}

Percentage of investors with a positive total of sign matches of excess return and excess bids according to the adaptive model and predictive model ( $p$-value of Wilcoxon-sign test) [standard deviation across independent sessions].

\begin{tabular}{lll}
\hline & Adaptive model & Predictive model \\
\hline Average portfolio & $89(0.016)$ & $91(0.016)$ \\
& {$[7.36]$} & {$[4.01]$} \\
Average asset L & $88(0.016)$ & $90(0.016)$ \\
& {$[2.83]$} & {$[8.30]$} \\
Average asset M & $80(0.016)$ & $87(0.016)$ \\
& {$[10.65]$} & {$[10.60]$} \\
Average asset R & $85(0.016)$ & $89(0.016)$ \\
& {$[5.56]$} & {$[9.56]$} \\
\hline
\end{tabular}

(A.2)

(ix) Data analysis (observation 6):The random simulation success rates of observation 4 provide a useful benchmark measure. In this paragraph, we report some measures that can be viewed as robustness checks on the validity of our adaptive models. The first such test enhances the success rate in the simulation. Instead of drawing ranks at random, the adaptive models' predicted ranks are reshuffled for each subject's data. For example, the predicted triple ranks vector according to the SIZE model (10) on the data of subject \#1 for the periods $3 . . .50$ is reshuffled, randomly drawn without replacement and assigned in a random order to periods 3.50. The ranks of the subjects' excess bids in each period are matched with the reshuffled prediction and success rates are totaled over the periods. The success rate of the reshuffled predictions is totaled over all subjects. By repeating this reshuffling-simulation 10,000 times, we generate a model-specific individual success-rate distribution (in this example for the SIZE-model). The distribution of total success rates dominates the one of the random simulation model. However, the observed total success rate aggregated over all subjects, $I$, is larger than in (almost) all of the 10,000 reshuffled simulation runs for the models PATH, BP, DY, and SIZE. For MOM, in contrast, more than $40 \%$ of the reshuffled simulations imply larger total success rates than the observed total. So, MOM fails this robustness test.

The static and predictive pendants to our adaptive models are compared on independent session level, and the two-tailed Wilcoxon signed ranks test is applied to measure significance.

(a) The static model is a constant strategy that has to be applied to the ranked data. For instance, MOM is a static strategy as it constantly suggests an equalizing of the excess-bids ranks with the excess-return ranks, and the PATH strategy is a static model too. We investigate static value-style strategies that equalize the predicted excess-bids ranks with the observed value ranks, basically implying to put the low-value security underweight and overweight the high-value security ("high minus low" or HML). We also investigate the static size-strategy that equalizes the predicted excessbid ranks with the reverse size ranks ("small minus big" or SMB). We find higher success rates for each session with the PB and DY than with the static HML strategy; both $p$-values are 0.0180 for the seven independent sessions. However, the adaptive SIZE model, SMB, leads to higher success rates than the static model on only two of the seven sessions; the differences between the outcomes are thus not significant. The relatively high performance of the static SIZE model may be attributable to the fact that value-style investing frequently recommends the same strategy as the static SIZE model in our environment. Adaptive value-style investing provides the highest goodness of fit among the considered models in our data.

(b) The predictive model is dynamic, alike the static model. The predictive model anticipates the model ranking of the following period and ranks the excess bids according to the available information. For instance, if we assume that (with perfect foresight) we know that tomorrow's returns will be highest on the intermediate-value security, second on the high-value security, and third on the low-value security, the predictive value-style investor applies the corresponding excess-bids ranks to the current value ranks, i.e., overweight excess bids on the current intermediate-value security. The predictive MOM strategy puts overweight on the anticipated (this period's) high return security, and so on. The session totals for each of the predictive models MOM, SIZE, PB and DY are computed involving periods 2..49, but otherwise the computation follows the same steps as with the adaptive models. The result is that for each model and independent session the success rate of the adaptive model exceeds the one of the predictive pendant; the $p$-value is thus always 0.0180 .

\section{References}

Asparouhova, E., Bossaerts, P., Ledyard, J., 2016. Competitive off-equilibrium: theory and experiment Available at SSRN:. http://dx.doi.org/10.2139/ssrn. 2774301.

Asparouhova, E., Bossaerts, P., Plott, C.R., 2003. Excess demand and equilibration in multi-security financial markets: the empirical evidence. J. Financial Markets 6, 1-21.

Barberis, N., Shleifer, A., 2003. Style Investing. J. Financial Econ. 68, 161-199.

Barberis, N., Thaler, R., 2003. A survey of behavioral finance. In: Handbook of the Economics of Finance, 1, pp. 1053-1128.

Berk, J.B., Green, R.C., 2004. Mutual fund flows and performance in rational markets. J. Political Econ. 112 (6), 1269-1295. 
Bossaerts, P., Plott, C.R., 2008. From Market jaws to the newton method: the geometry of how a market can solve systems of equations. In: Plott, C.R., Smith, V.L. (Eds.). In: Handbook of Experimental Economics Results, Vol.1. Elsevier, Amsterdam, pp. 22-24.

Bhuyan, R., Chaudhury, M., 2005. Trading on the information content of open interest: Evidence from the US equity options market. Derivatives Use, Trad. Regul. 11 (1), 16-36.

Cason, T.N., Friedman, D., 1997. Price formation in single call markets. Econometrica 65 (2), 311-345.

Carle, T., Lahav, Y., Neugebauer, T., Noussair, C.N., 2018. Heterogeneity of beliefs and trade in experimental asset markets. J. Finan. Quant. Anal. forthcoming.

Charness, G. and T. Neugebauer, forthcoming, A test of the Modigliani-Miller invariance theorem and arbitrage in experimental asset markets, Journal of Finance.

Cason, T.N., Friedman, D., 1999. Learning in a laboratory market with random supply and demand. Exper. Econ. 2, 77-98.

Cason, T.N., Friedman, D., 2008. A comparison of market institutions. In: Plott, C.R., Smith, V.L. (Eds.). In: Handbook of Experimental Economics Results, 1. Elsevier, Amsterdam, pp. 264-272.

Fischbacher, Urs, 2007. z-Tree: Zurich toolbox for ready-made economic experiments. Exper. Econ. 10 (2), $171-178$.

Forsythe, R., Palfrey, T.R., Plott, C.R., 1982. Asset valuation in an experimental market. Econometrica 50 (3), $537-567$.

Goerg, S.J., Neugebauer, T., Sadrieh, A., 2016. Impulse response dynamics in weakest link games. German Econ. Rev. 17 (3), $284-297$.

Greiner, Ben, 2015. Subject pool recruitment procedures: organizing experiments with ORSEE. J. Econ. Sci. Assoc. 1 (1), $114-125$.

Haruvy, E., Lahav, Y., Noussair, C.N., 2007. Traders' expectations in asset markets: experimental evidence. Am. Econ. Rev. 97, 1901-1920.

Hommes, C., Lux, T., 2013. Individual expectations and aggregate behavior in learning-to-forecast experiments. Macroecon. Dyn. 17 (02), $373-401$.

Marshall, A., 1890. Principles of Economics, I. Macmillan, London.

Neugebauer, T., Selten, R., 2006. Individual behavior of first-price auctions: the importance of feedback information in experimental markets. Games Econ. Behav. 54, 183-204.

Plott, C.R., 2008a. Properties of disequilibrium adjustment in double auction markets. In: Plott, C.R., Smith, V.L. (Eds.). In: Handbook of Experimental Economics Results, 1. Elsevier, Amsterdam, pp. 16-21.

Plott, C.R., 2008b. Principles of market adjustment and stability. In: Plott, C.R., Smith, V.L. (Eds.). In: Handbook of Experimental Economics Results, 1. Elsevier, Amsterdam, pp. 214-227.

Plott, C.R., and K. Pogorelskiy, 2015, Call Market Experiments: Efficiency and Price Discovery Through Multiple Calls and Emergent Newton Adjustments, CalTech, Mimeo.

Plott, C.R., Sunder, S., 1982. Efficiency of experimental security markets with insider information: an application of rational expectation models. J. Political Econ. 90, 663-698.

Plott, C.R., Sunder, S., 1988. Rational expectations and the aggregation of diverse information in a laboratory security markets. Econometrica 56, $1085-1118$.

Selten, R., 2004. Learning direction theory and impulse balance equilibrium. In: Friedman, D., Cassar, A. (Eds.), Economics Lab - An Intensive Course in Experimental Economics. Routledge, NY, pp. 133-140.

Selten, R., Buchta, J., 1999. Experimental sealed bid first price auctions with directly observed bid functions. In: Rapoport, A., Budescu, D.V., Erev, I., Zwick, R. (Eds.), Games and Human Behavior: Essays in Honor of Amnon Rapoport. Lawrence Erlbaum, pp. 101-116.

Selten, R., Neugebauer, T., 2013. Stock Market "Puzzles" Observed in the Experimental Call Auction and Continuous Double Auction Market - A Comparison of the Two Market Institutions. University of Luxembourg, Mimeo.

Selten, R., Stoecker, R., 1986. End behavior in sequences of finite prisoners' dilemma supergames: a learning theory approach. J. Econ. Behav. Organ. 7, 47-70.

Smith, V., Suchanek, G., Williams, A., 1988. Bubbles, crashes, and endogenous expectations in experimental spot asset markets. Econometrica 56, 1119-1151. Statman, M., Thorley, S., Vorkink, K., 2006. Investor overconfidence and trading volume. Rev. Financial Stud. 19 (4), $1531-1565$.

Van Boening, M.V., 1991. Call versus continuous auctions: An experimental study of market organization (Ph.D. thesis). University of Arizona.

Van Boening, M., 2012. Excess bids and price dynamics in some experiments with long-lived assets. In: Proceedings of the conference Experimental Finance in Luxembourg.

Walras, L., 1954. Elements of Pure Economics: Or the Theory of Social Wealth, Homewood, Ill: Richard D. Irwin, Inc. 